\title{
Three new species of Rhaphium Meigen, 1803 from mangroves in Hong Kong (Diptera: Dolichopodidae: Rhaphiinae)
}

\author{
Patrick GROOTAERT $^{1, *}$, Christopher TAYLOR ${ }^{2} \&$ Benoit GUÉNARD $^{3}$ \\ ${ }^{1}$ Royal Belgian Institute of Natural Sciences, Vautierstraat 29, 1000 Brussels, Belgium and \\ Lee Kong Chian Natural History Museum, National University of Singapore, Singapore. \\ ${ }^{2,3}$ School of Biological Sciences \& The University of Hong Kong, Kadoorie Biological Sciences \\ Building Pokfulam Road, Hong Kong, PRC. \\ *Corresponding author: pgrootaert@yahoo.co.uk \\ ${ }^{2}$ Email: pantopsalis@hotmail.com \\ ${ }^{3}$ Email: zeroben@gmail.com \\ ${ }^{1}$ urn:lsid:zoobank.org:author:B80BC556-9087-4D0D-9D69-7FA9BE5779C4 \\ ${ }^{2}$ urn:1sid:zoobank.org:author:E3E5CF0B-8C80-477E-8ED6-F78242F8D06F \\ ${ }^{3}$ urn:lsid:zoobank.org:author:3885FFD6-3FE4-428A-88BD-C5E88F2BC315
}

\begin{abstract}
The genus Rhaphium Meigen, 1803 is recorded for the first time from mangroves in Hong Kong. Three species are described as new to science: Rhaphium hongkongense sp. nov. and Rhaphium spinulatum sp. nov., both tentatively belonging to the Rhaphium crassipes group sensu Negrobov \& Grichanov (2010), and Rhaphium canniccii sp. nov. assigned to a new species group, the Rhaphium micans group. The status of Rhaphium mediocre (Becker, 1922) described from Taiwan and Rhaphium eburnea (Parent, 1926) from Shanghai is discussed. NGS barcodes for the new species are provided.
\end{abstract}

Keywords. Rhaphium new species, mangrove, Hong Kong.

Grootaert P., Taylor C. \& Guénard B. 2019. Three new species of Rhaphium Meigen, 1803 from mangroves in Hong Kong (Diptera: Dolichopodidae: Rhaphiinae). European Journal of Taxonomy 540: 1-21.

https://doi.org/10.5852/ejt.2019.540

\section{Introduction}

Mangrove forests in China, including the Hong Kong SAR, have been subject to extensive destruction in recent decades, leading to concerns about the health of surviving mangroves in the region (Tam \& Wong 2002). The insect fauna associated with mangroves in Hong Kong is poorly understood, with few studies examining the occurrence of species in this habitat. In 2017, a survey of mangrove insects was conducted, including the placement of Malaise traps at a number of sites around the Hong Kong SAR. Among the more numerous insect taxa found in this survey were long-legged flies of the family Dolichopodidae.

Dolichopodid species are well adapted to mangrove conditions, as summarized by Grootaert (2009), and several genera like Physopyga Grootaert \& Meuffels, 1990, Ngirhaphium Evenhuis \& Grootaert, 2002 
and Phacaspis Meuffels \& Grootaert, 1988 are exclusive to mangroves (Grootaert \& Puniamoorthy 2014). In addition, many genera that thrive in terrestrial habitats also have species that are exclusive to mangroves. Examples are Hercostomus Loew, 1857 (Zhang et al. 2008; Ramos \& Grootaert 2018), Paraclius Loew, 1864 (Zhang et al. 2007) and Teuchophorus Loew, 1857 (Grootaert 2006). To the best of our knowledge, the genus Rhaphium Meigen, 1803 is here recorded for the first time in mangroves. These records are not accidental, since the species were found in high abundance and at several mangrove sites all around Hong Kong. The new species have not yet been recorded from terrestrial forest.

At the moment, 29 species of Rhaphium are known from China. Yang et al. (2011) reported 20 species and Tang et al. (2016) added another six species from Tibet (one species) and Inner Mongolia (five species). Recently, Qilemoge et al. (2019) described another three species from Qinghai and Gansu Provinces in Tibet as well as from Beijing and Hebei. Rhaphium is very diverse in temperate climates, but is rare under a tropical climate (Yang et al. 2006). The present records of Rhaphium in Hong Kong, which has a subtropical climate with marked hot and cooler seasons, are probably the southernmost for this genus at sea level in Southeast and East Asia.

Tang et al. (2016) gave an overview of the systematic relationships within the subfamily Rhaphiinae and provided a key to all the Chinese species of Rhaphium except $R$. dilatatum Wiedemann, 1830 and $R$. relatus (Becker, 1922), which require re-description. An updated key including new species from Tibet, Beijing and Hebei Province was provided by Qilemoge et al. (2019).

Here, we describe three species as new for science. NGS barcodes of all three are made available for future study of the haplotype networks of these species. The status of Rhaphium mediocre (Becker, 1922) described from Taiwan and R. eburnea (Parent, 1926) from Shanghai is discussed.

\section{Material and methods}

The specimens studied in the present paper were collected as part of a general biodiversity survey of Hong Kong mangroves in which 26 sites were surveyed through the use of Malaise traps for two weeks per site ranging from October 2017 to July 2018. A large number of arthropods, including many dolichopodid species, were collected and preserved in $70 \%$ ethanol.

Holotypes and paratypes are conserved in the collections of the Royal Belgian Institute of Natural Sciences in Brussels (RBINS) and in the Natural History Museum of the University of Hong Kong (HKU). Voucher specimens are deposited in HKU and the Lee Kong Chian Natural History Museum in Singapore (LKCNH). The labels of the specimens contain the original indication of the collection sites: e.g., 28M1: 28 refers to the station Tai Tan while M1 refers to the collection period at that site, 5-19 December 2017.

Material was NGS barcoded following the technique of Meier et al. (2016). This includes a pre-sorting into clusters before the identification process. 587 specimens were successfully barcoded resulting in 3 clusters of Molecular Operational Taxonomic Units below 3\% (mOTUs) that were congruent with the morpho-species described below.

Abbreviations used in the text:

$\mathrm{ad}=$ anterodorsal

$\mathrm{dc}=$ dorsocentral bristles

$\mathrm{pd}=$ posterodorsal

The stacked habitus images were made according to Brecko et al. (2014). 


\title{
Results
}

\author{
Phylum Arthropoda von Siebold, 1848 \\ Order Diptera Linnaeus, 1758 \\ Family Dolichopodidae Latreille, 1809 \\ Subfamily Rhaphiinae Bigot, 1852
}

Genus Rhaphium Meigen, 1803

\section{Type species}

Rhaphium macrocerum Meigen, 1824.

\section{Diagnosis}

Rhaphium may be recognised by the following features (Tang et al. 2016): vertex flat; ocellar seta nearly as long as vertical seta; face distinctly narrower than frons; clypeus not distinctly separated from face; antenna black, postpedicel elongate, 2 to $8 \times$ as long as wide, arista apical; propleuron without distinct bristle but with dense white hairs; hind coxa with or without an exterior bristle near middle; mid and hind femora both with preapical bristle(s); wing vein $\mathrm{M}$ straight and not bifurcated, $\mathrm{R}_{4+5}$ apically parallel with $\mathrm{M}$ or slightly convergent, $\mathrm{CuAx}$ ratio less than 1 ; abdominal segments 1-3 usually with long pale hairs, segment 6 visible and hairy; male terminalia small, connected tightly with pregenital segment, hidden in apex of abdomen, cap-like, cercus long and narrowed towards tip, with hairs and bristles.

\section{Raphium crassipes species group}

The following two species are provisionally included in the Rhaphium crassipes group sensu Negrobov \& Grichanov (2010), mainly on the base of the structure of the male terminalia as discussed below.

Rhaphium hongkongense sp. nov. urn:Isid:zoobank.org:act:69130531-6D7A-4CA4-BAEF-6D6FF5E35AC5

Figs 1-2

\section{Diagnosis}

Small species with long postpedicel (almost $5 \times$ as long as wide), biseriate acrostichals, five pairs of dorsocentral bristles, simple cerci and apically simple surstyli. Fore tarsomere 1 ventrally produced, bearing only minute apical spines. Surstylus yellowish, with club-shaped tip.

\section{Etymology}

The new species is named after the type locality Hong Kong.

\section{Material examined}

\section{Holotype}

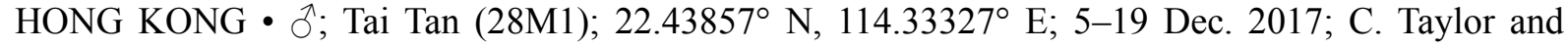
U. Chang leg.; muddy front mangrove near forest; RBINS.

\section{Paratypes}

HONG KONG • 47 ex.; same collection data as for holotype; barcoded; RBINS • $4 \hat{\partial} \hat{\jmath}, 1$ क; Sam A. Tsuen (5AM1); $22.51534^{\circ} \mathrm{N}, 114.27121^{\circ} \mathrm{E}$; 11-27 Dec. 2017; C. Taylor and U. Chang leg.; muddy back mangrove; RBINS • 1 ex.; To Kwa Peng (29M1); $22.42863^{\circ}$ N, $114.33314^{\circ}$ E; 29 Nov. -5 Dec. 2017 ; C. Taylor and U. Chang leg.; barcoded; RBINS • 6 ex.; Sai Keng (40M1); $22.42041^{\circ}$ N, $114.26796^{\circ}$ E; 
18 Dec. 2017-2 Jan. 2018; C. Taylor and U. Chang leg.; barcoded; RBINS • 3 ex.; Ho Chung (Nam Wai) (38AM1); $22.35347^{\circ} \mathrm{N}, 114.25622^{\circ} \mathrm{E}$; 4-18 Dec. 2017; C. Taylor and U. Chang leg.; barcoded; RBINS - 72 ex.; Sam A Tsuen (5AM1); 22.51534 N, 114.27121 ${ }^{\circ}$ E; 11-27 Dec. 2017; C. Taylor and U. Chang leg.; barcoded; RBINS -26 ex.; Sam A Chung (5BM1); $22.50829^{\circ} \mathrm{N}, 114.27248^{\circ}$ E; 11-27 Dec. 2017; C. Taylor and U. Chang leg.; barcoded; RBINS 1 ภ, 1 ; ; same collection data as for preceding; barcoded; HKU.

\section{Barcodes}

The barcodes below can be copy/pasted into a fasta file in order to compare with other species.

>doli_HKC0000723_Kareen_INTRN220_HongKong_31Dec9999_20180820 male Sam A Tsuen (5AM1)

AAATAAATGTTGATATAATACAGGGTCACCACCTCCTGCGGGATCAAAAAATGAAGTATTTA AGTTTCGGTCTGTTAATAGTATGGTGATGGCTCCTGCTAATACTGGTAATGATAATAATAATA GAATAGCTGTAATTACTACAGATCAGACAAATAAAGGTATACGATCTAATGTAATTCCTGTG GATCGTATATTAATAACTGTTGTAATGAAATTCACTGCTCCTAGAATTGATGAAATTCCGGCT AAATGTAATGAAAAAATAGCTAAATCTACAGAGGCACCTCCATGAGCAATTCCTGCTGAGA GG

>doli_HKC0000712_Kareen_INTRN220_HongKong_31Dec9999_20180820 female Sam A Tsuen (5AM1)

AAATAAATGTTGATATAATACAGGGTCACCACCTCCTGCGGGATCAAAAAATGAAGTATTTA AGTTTCGGTCTGTTAATAGTATGGTGATGGCTCCTGCTAATACTGGTAATGATAATAATAATA GAATAGCTGTAATTACTACAGATCAGACAAATAAAGGTATACGATCTAATGTAATTCCTGTG GATCGTATATTAATAACTGTTGTAATGAAATTCACTGCTCCTAGAATTGATGAAATTCCGGCT AAATGTAATGAAAAAATAGCTAAATCTACAGAGGCACCTCCATGAGCAATTCCTGCTGAGA GG

\section{Description}

Male

Measurements. Body: 2.3-2.4 mm long; wing: 2.45-2.5 mm long.

HEAD. Antenna with scape and pedicel yellowish brown, postpedicel brownish black; arista black. Postpedicel $5 \times$ as long as wide; arista short (a third of the length of the postpedicel); basal aristal segment short, $0.15 \times$ length of arista $(0.0225 \mathrm{~mm} / 0.15 \mathrm{~mm})$. Palpus yellowish. Vertical bristles a little shorter than ocellars. Upper four postoculars black, lower postoculars whitish, multiseriate.

Thorax. Acrostichals biseriate, rows close together, present on anterior half of mesonotum. 5 long dorsocentrals, equally long. A pair of long scutellar bristles.

Legs. Yellow except mid and hind coxae anteriorly brownish, hind femur and tibia dusky yellowish. Fore and mid tarsomeres 3, 4 and 5 brown; hind tarsomere 1 with brown tip, following tarsomeres entirely brown.

ForE LEG. Coxa with short anterior bristles and one or two black bristles (Fig. 2A). Femur with one preapical posteroventral bristle. Tibia with one dorsal at basal quarter (Fig. 2C). Tip of tarsomere 1 ventrally with short spinules, tip produced, bearing minute curved apical spines (Fig. 2D).

MID LEG. Coxa with a fine brown exterior bristle. Femur with a preapical anterior and a larger posterior. Tibia with one long anterodorsal on basal $1 / 5$, one shorter posterodorsal and one anterodorsal near middle. 


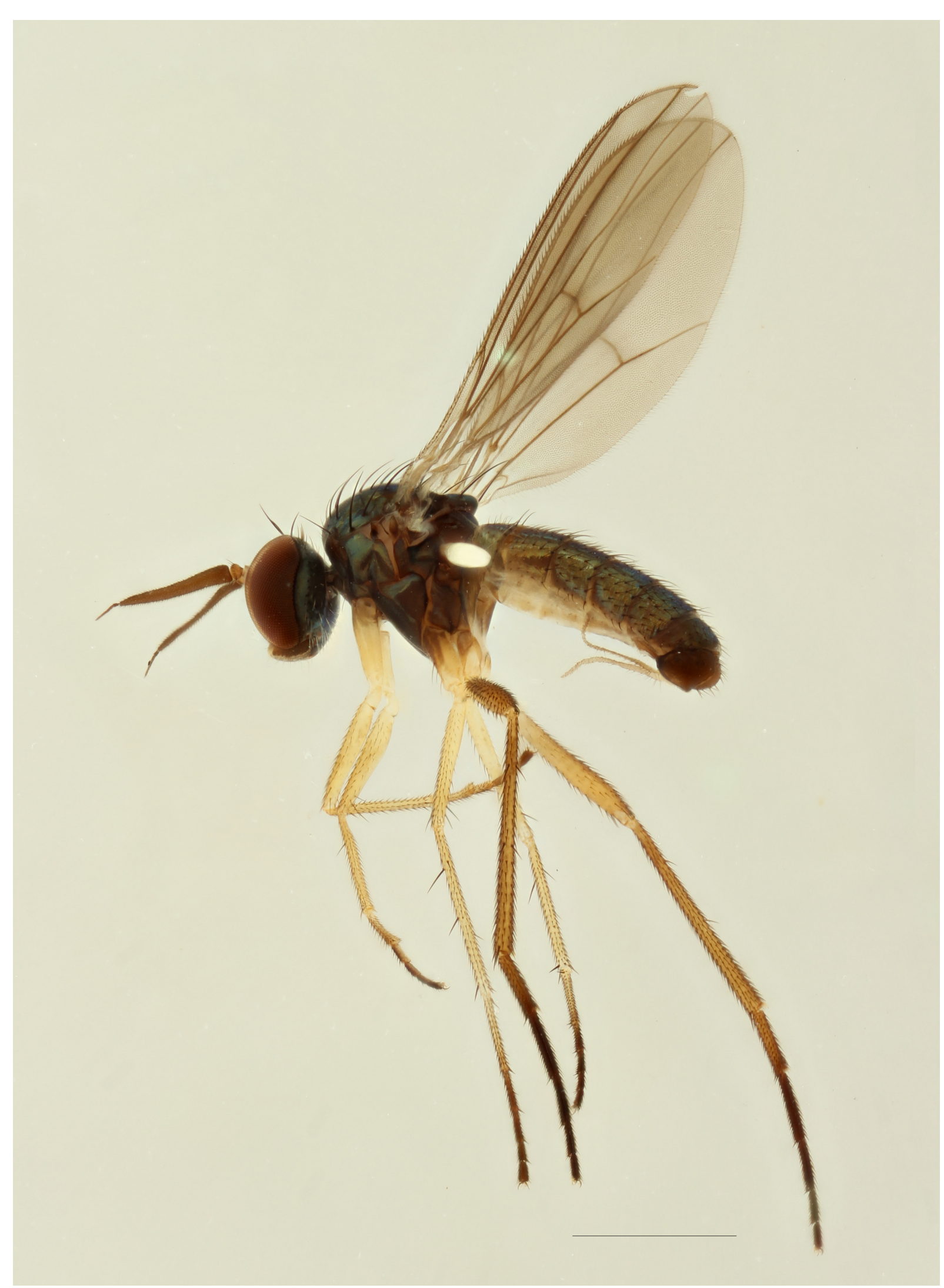

Fig. 1. Rhaphium hongkongense sp. nov., holotype, $\widehat{\jmath}$, habitus (RBINS). Scale bar: $1 \mathrm{~mm}$. (Photo credit Ms Camille Locatelli) 
HIND LEG. Hind coxa lacking an exterior bristle. Femur with an indistinct anterior preapical, minute ventrals. Tibia with two anterodorsals, two posterodorsals and an apical crown of bristles.

WING. Brownish with brown veins (Fig. 1). Squama white with white cilia. Haltere white.

AвDomen. Paler than thorax, venter yellowish with minute hairs. Only tergite 1 with long marginal bristles.

Male terminalia (Fig. 2). Surstylus yellowish, with club-shaped tip (Fig. 2E). Cercus whitish, very long and thin, its tip reaching tip of sternite 3 .

\section{Female}

MEASuREMENTs. Body: 2.56-2.6 mm long; wing 2.5-3 mm long.

HEAD. Antenna shorter than in male. Scape and pedicel yellow, postpedicel and arista black. Postpedicel about $3-3.5 \times$ as long as wide. Arista longer than postpedicel (about $1.2 \times$ ).

LEGS. Fore coxa with a few short black bristles near tip. Fore tibia with 2 long preapical posteroventrals.

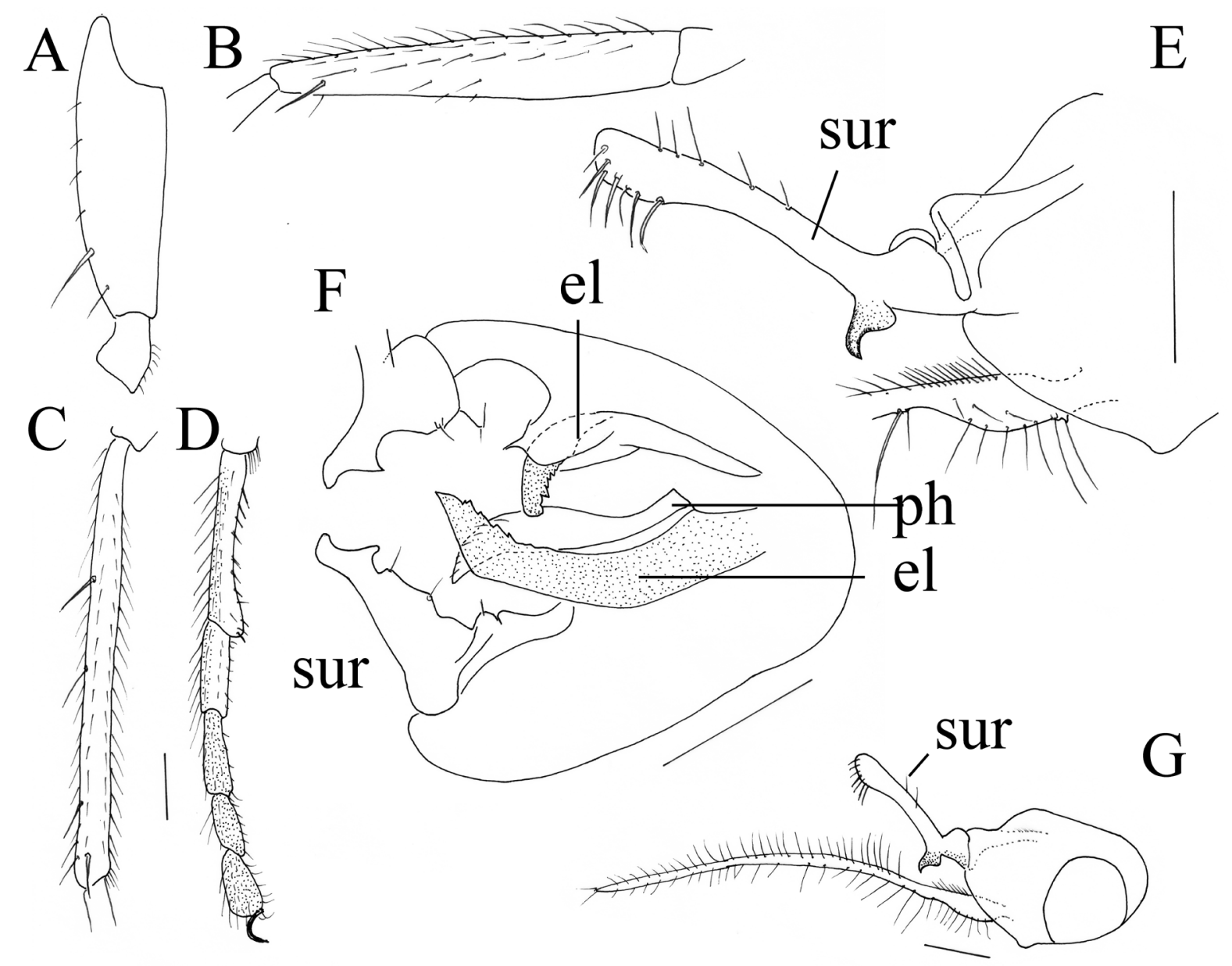

Fig. 2. Rhaphium hongkongense sp. nov., holotype, $\widehat{\partial}$ (RBINS). A. Fore coxa. B. Fore femur. C. Fore tibia. D. Fore tarsomeres. E. Surstylus, lateral view. F. Epandrium, ventral view. G. Epandrium with cerci, lateral view. Scale bar: $0.1 \mathrm{~mm}$. Abbreviations: $\mathrm{el}=$ epandrial lobe; $\mathrm{ph}=$ phallus; $\mathrm{sur}=$ surstylus. Scale bars: $0.1 \mathrm{~mm}$. 


\section{Remarks}

Rhaphium hongkongense sp. nov. and $R$. spinulatum sp. nov. may be distinguished from other species of Rhaphium in China by the combination of a postpedicel 5-6 $\times$ as long as wide, biseriate acrostichals, five pairs of dorsocentral bristles, simple cerci and apically simple surstyli.

In having five dc and fore coxa yellow, mid and hind coxae black (or at least brownish anteriorly), the surstylus with only sparse short hairs and the cercus long triangular, the two new species come close to R. qinghaiense Yang, 1998 (Yang et al. 2011: fig. 810). However, in the latter the hind tibia is black, the postpedicel is shorter, the cercus is also shorter and differently shaped (broad at base, $4 \times$ as long as wide) and the surstylus is also different.

In the key to Chinese Rhaphium provided by Tang et al. (2016), both $R$. hongkongense sp. nov. and $R$. spinulatum sp. nov. would key out between $R$. furcatum Yang \& Saigusa, 2000 and $R$. palliaristatum Yang \& Saigusa, 2001. Both species may be distinguished from $R$. palliaristatum by the colour of the basal antennal segments (uniformly black or brown rather than pale yellow with a black base), and from $R$. furcatum by the presence of acrostichal bristles and the apically non-bifurcated surstylus. Rhaphium hongkongense sp. nov. is larger than $R$. spinulatum sp. nov. The basal aristal segment is shorter. The tip of the fore tarsomere 1 is more produced, but apical spinules are indistinct. The surstylus is yellowish with a club-shaped tip, while in $R$. spinulatum sp. nov. the surstylus is black, with a slender, pointed tip. The mid coxa has a fine brown exterior bristle and the mid coxa bears a white exterior bristle.

Rhaphium spinulatum sp. nov. urn:1sid:zoobank.org:act:5CFE7569-8A05-4D7B-AC60-5AA30F5A0C87

Figs 3-4

\section{Diagnosis}

Small species with a long postpedicel, almost $6 \times$ as long as wide, biseriate acrostichals, five pairs of dorsocentral bristles, simple cerci and surstyli apically simple. Scape and pedicel brown like postpedicel. Fore tarsomere 1 ventrally not produced, bearing a pair of curved apical spines. Surstylus dark brown.

\section{Etymology}

The new species is named after the distinctive spinules on the apex of the first tarsomere of the fore leg.

\section{Material examined}

\section{Holotype}

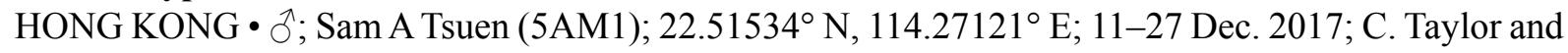
U. Chang leg.; muddy back mangrove; RBINS.

\section{Paratypes}

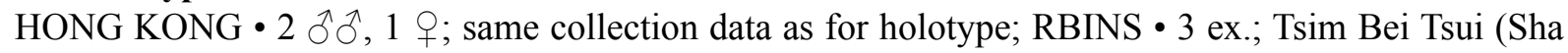
Kiu Tsuen) (9EM1); $22.48902^{\circ} \mathrm{N}, 113.99832^{\circ}$ E; 31 Oct.-15 Nov. 2017; C. Taylor and U. Chang leg.; barcoded; RBINS • 9 ex.; To Kwa Peng (29M1); $22.42863^{\circ}$ N, $114.33314^{\circ}$ E; 29 Nov.-5 Dec. 2017; C. Taylor and U. Chang leg.; barcoded; RBINS • 22 ex.; Ho Chung (Nam Wai) (38AM1); $22.35347^{\circ} \mathrm{N}$, 114.25622 ${ }^{\circ}$ E, 4-18 Dec. 2017; C. Taylor and U. Chang leg.; barcoded; RBINS • 13 ex.; Ho Chung (38BM1); $22.35366^{\circ} \mathrm{N}, 114.25207^{\circ} \mathrm{E}$; 4-18 Dec. 2017; C. Taylor and U. Chang leg.; barcoded; RBINS - 242 ex.; Tai Tan (28M1); $22.43857^{\circ}$ N, $114.33327^{\circ}$ E, 5-19 Dec. 2017; C. Taylor and U. Chang leg.;

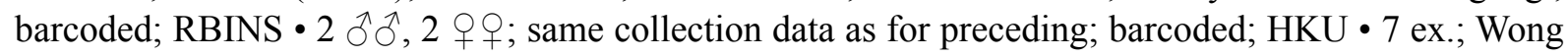
Chuk Wan (34M1); 22.39563 ${ }^{\circ}$ N, $114.28617^{\circ} \mathrm{E}$; 5-19 Dec. 2017; C. Taylor and U. Chang leg.; barcoded; RBINS • 2 ex.; Sam A Tsuen (5AM1); 22.51534 N, 114.27121 ${ }^{\circ}$ E; 11-27 Dec. 2017; C. Taylor and 
U. Chang leg.; barcoded; RBINS • 91 ex.; Sam A Chung (5BM1); 22.50829 N, 114.27248 ${ }^{\circ}$ E; 11-27 Dec. 2017; C. Taylor and U. Chang leg.; barcoded; RBINS • 34 ex.; Sai Keng (40M1); $22.42041^{\circ}$ N, 114.26796 E; 18 Dec. 2017-2 Jan. 2018; C. Taylor and U. Chang leg.; barcoded; RBINS.

\section{Barcodes}

The barcodes below can be copy/pasted into a fasta file in order to compare with other species.

>doli_HKC0000197_Kareen-Nabilah_INTRN223_HongKong_31Dec9999_20180820 male Ho Chung (Nam Wai) 38AM1

GAATAAATGTTGATATAGTACAGGGTCTCCTCCTCCTGCGGGGTCGAAGAATGATGTATTT AAATTACGATCTGTTAATAACATAGTAATAGCTCCGGCTAGTACTGGTAATGATAATAATA ATAGAATTGCTGTAATTACTACAGATCAAACAAATAAGGGCATTCGGTCAAGAGTAATTCC AGTGGATCGTATATTAATTACTGTTGTAATAAAATTTACTGCCCCTAAAATTGATGAAATACC GGCAAGATGTAAAGAAAAAATAGCTAAATCAACAGAGGCACCACCATGAGCAATACCTGC AGACAGA

>doli_HKC0000137_Kareen-Nabilah_INTRN222_HongKong_31Dec9999_20180820 female Tai Tan $28 \mathrm{M} 1$

GAATAAATGTTGATATAGTACAGGGTCTCCTCCTCCTGCGGGGTCGAAGAATGATGTATT TAAATTACGATCTGTTAATAACATAGTAATAGCTCCGGCTAGTACTGGTAATGATAATAAT AATAGAATTGCTGTAATTACTACAGATCAAACAAATAAGGGCATTCGGTCAAGAGTAATT CCAGTGGATCGTATATTAATTACTGTTGTAATAAAATTTACTGCCCCTAAAATTGATGAAATA CCGGCAAGATGTAAAGAAAAAATAGCTAAATCAACAGAGGCACCACCATGAGCAATACCT GCAGACAGA

\section{Description}

\section{Male}

Measurements. Body: 2-2.1 mm long; wing: 2.1-2.4 mm long.

HEAD. Face narrow, parallel-sided, a little wider than postpedicel. Antenna uniformly brown. Postpedicel almost $6 \times(5.8)$ as long as wide; arista short (a third of the length of the postpedicel); basal aristal segment short. Palpus yellowish, with a small pale brown bristle. Vertical bristles twice as long as ocellars. Postoculars all whitish, uniseriate above, multiseriate and densely set below.

THorax. Acrostichals short, biseriate, rows close together, present on basal $2 / 3$ of mesonotum. Five long dorsocentrals equally long, with a short bristle in front. A pair of long scutellars.

LEGS. Yellow, but base of fore coxa brown, mid and hind coxae anteriorly brownish, hind leg with knee brown (tip of femur and base of tibia). Fore tarsus with tarsomeres 2-4 brown above, apical tarsomere entirely brown. Mid and hind leg with only tarsomeres 4 and 5 brown.

ForE LEG. Coxa with long pale bristles (Fig. 3). Femur with three preapical posteroventral bristles. Tibia with a long dorsal preapical and a ventral row of bristles, nearly as long as tibia is wide. Tarsomere 1 with a ventral row of bristly hairs (Fig. 4A); its tip is ventrally not produced and bears a pair of curved apical spines.

MID LEG. Coxa with white bristles anteriorly and a white exterior. Femur with a preapical anterior, one preapical posteroventral and two distinct posteriors. Tibia with two short ad and an apical crown of short bristles. 
HIND LEG. Coxa with a white exterior bristle. Tibia with a short ad and pd in basal third and a short ad and pd in apical third; apical crown with short bristles.

WING. Brownish tinged with brown veins (Fig. 3). Squama white with long white cilia. Haltere white.

AвDOMEn. Same colouration as thorax, venter paler, with minute hairs. Only tergite 1 with long marginal bristles.

Male terminalia (Fig. 4). Surstylus dark brown, with a pointed tip (Figs 3, 4C). Cercus whitish, very long and thin, its tip reaching beyond tip of sternite 3 .

\section{Female}

MEASUREMENTS. Larger than male. Body: 2.5-2.6 mm long; wing 2.3-2.6 mm long.

HEAD. Face parallel-sided, wide, nearly $4 \times$ as wide as postpedicel. Scape and pedicel brown (not so dark as postpedicel); postpedicel black, elongate triangular, shorter than in male, 4-4.5 $\times$ as long as wide, about $1.5 \times$ as long as arista.

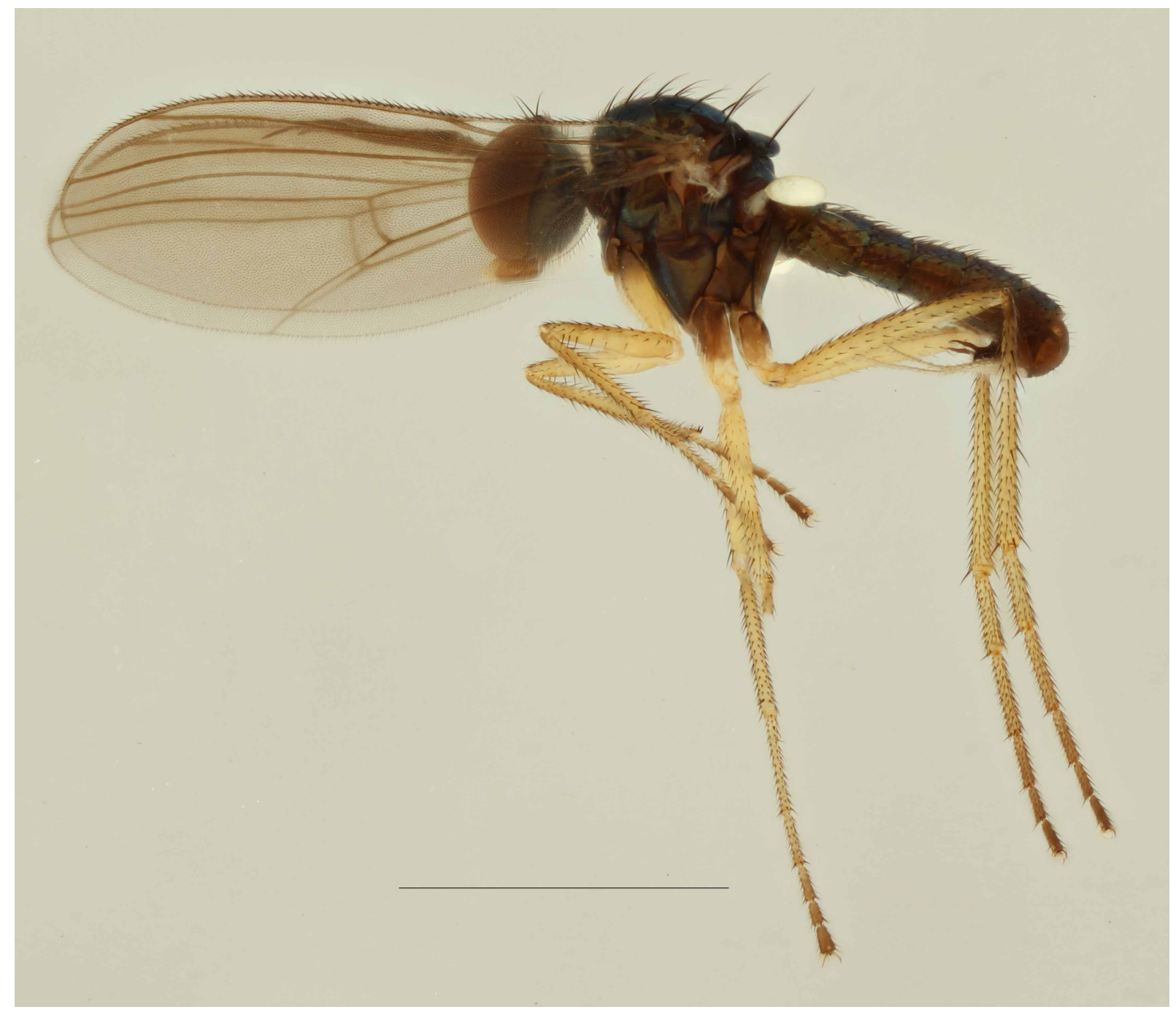

Fig. 3. Rhaphium spinulatum sp. nov., holotype, $\widehat{\jmath}$, habitus (RBINS). Scale bar: $1 \mathrm{~mm}$. (Photo credit Ms Camille Locatelli) 
Legs. Fore coxa with long white bristles over entire posterior margin (shorter in male). Bristles of posteroventral row in apical half of fore tibia less distinct than in male. Fore tarsomere 1 without apical spines.

\section{Remarks}

See under $R$. hongkongense sp. nov. for characters distinguishing this species from Rhaphium outside of Hong Kong. Rhaphium spinulatum sp. nov. is smaller than $R$. hongkongense sp. nov. The basal aristal segment is longer. The tip of fore tarsomere 1 is not produced but bears a pair of distinct apical spinules. Coxae 2 and 3 both bear a white exterior bristle. The surstylus is black, with a slender, pointed tip.

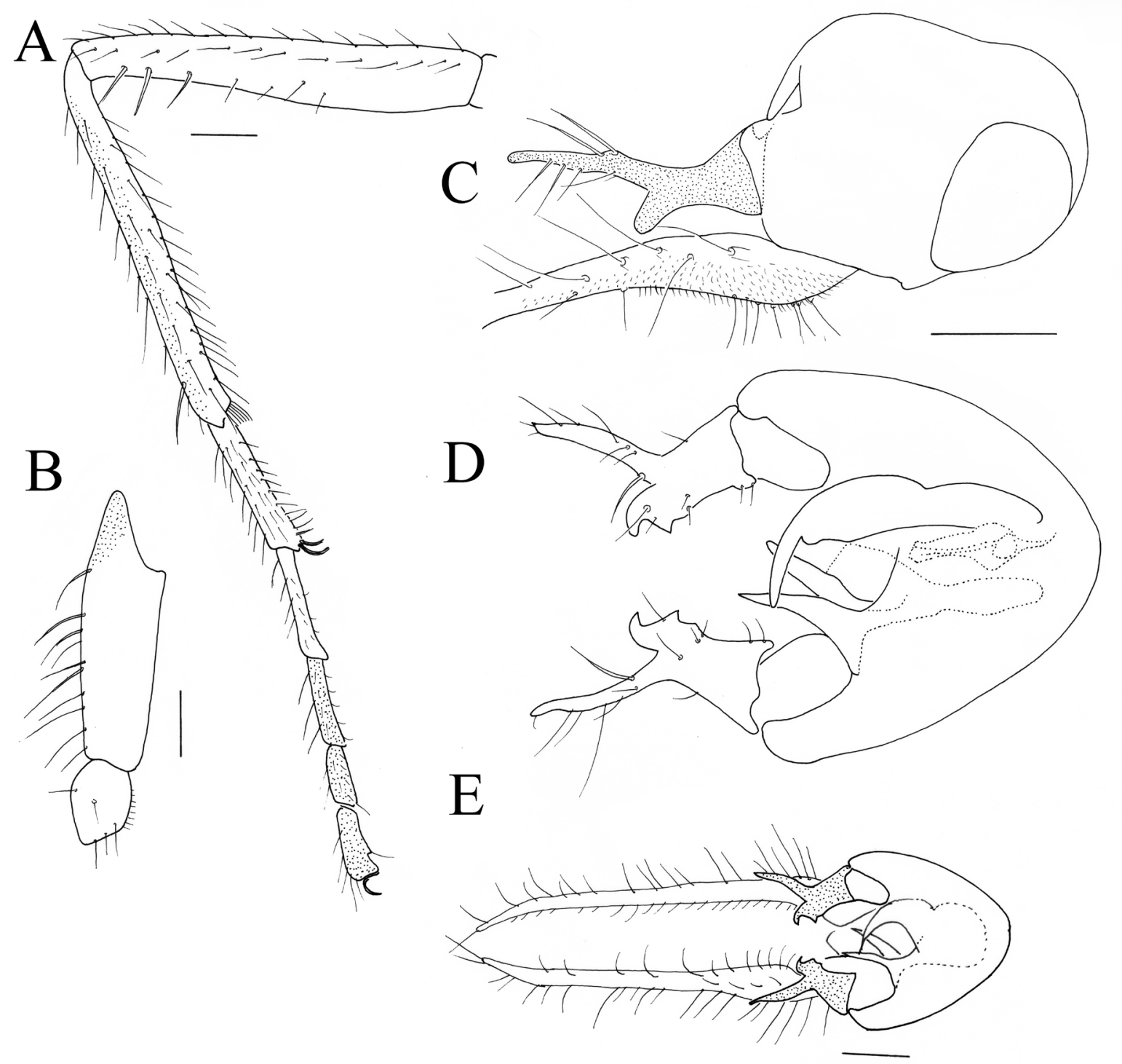

Fig. 4. Rhaphium spinulatum sp. nov., holotype, ô (RBINS). A. Fore leg, posterior view. B. Fore coxa. C. Epandrium, lateral view. D. Epandrium, ventral view. E. Epandrium with cerci, ventral view. Scale bars: $0.1 \mathrm{~mm}$. 


\section{Discussion of the systematic position}

Rhaphium hongkongense sp. nov. and R. spinulatum sp. nov. both have a long postpedicel, respectively 5 and $6 \times$ as long as wide, a simple arista, $5 \mathrm{dc}$, and a simple long elongate cercus not bifurcate and lacking a bundle of apical bristles.

Tang et al. (2016) and Qilemoge et al. (2019) give an overview of the attempts to classify the species of Rhaphium into species groups (Naglis 2009; Naglis \& Grootaert 2011; Negrobov \& Grichanov 2010). Rhaphium hongkongense sp. nov. and $R$. spinulatum sp. nov. are close to the $R$. bilobum group, defined by Tang et al. (2016) in having the postpedicel of the antenna at least $6 \times$ as long as wide, the arista as long as the width of the postpedicel, and $5 \mathrm{dc}$. However, in species of this group, the cercus of the male genitalia is bi-foliate, with two simple lobes, whereas $R$. hongkongense sp. nov. and $R$. spinulatum $\mathrm{sp}$. nov. have simple cerci.

The two new species are more plausibly classified in the $R$. crassipes group sensu Negrobov \& Grichanov (2010), which they resemble in the basic structure of the surstylus, epandrial lobe and cercus, though they differ from other species of the group, which have the male tarsomeres 4 and 5 of the mid leg black, dilated and dorsoventrally flattened. Despite this last distinction, $R$. hongkongense sp. nov. and $R$. spinulatum sp. nov. are very similar in the structure of the male terminalia to $R$. johnrichardi Negrobov \& Grichanov, 2010, described from the Sikhote Alin reserve in Promorsky Krai (Far East Russia).

\section{Rhaphium micans species group}

The Rhaphium micans species group is a new species group containing species with a triangular postpedicel (first flagellomere), at most $2.5 \times$ as long as wide, with arista longer than postpedicel (1.5 to $3 \times$ ), $5 \mathrm{dc}$ and long flattened cerci (nearly twice as long as epandrium), combined with in lateral view short rounded surstyli and a twisted short, but erect hypandrium.

\section{Rhaphium canniccii sp. nov. urn:lsid:zoobank.org:act:273DCEE4-22B1-4048-A32A-912C21B01D1A}

Figs 5-6

\section{Diagnosis}

Medium-sized species (4.3-4.8 mm long). Legs yellow, but tip of hind femur, base and tip of hind tibia and all hind tarsomeres black. Postpedicel elongate triangular, 1.6-1.7 $\times$ as long as wide, arista 1.6-2 $\times$ as long as postpedicel. Fore coxa with long bristles, near base with white bristles, on apical half white bristles mixed with black bristles. 4 pairs of acrostichals and 5 dorsocentrals. Fore femur entirely yellow, with short white ventral bristles on basal half. Tip of mid coxa with a number of adhered bristles forming a thorn.

\section{Etymology}

The new species is dedicated to Prof. Dr Stefano Cannicci from the Hong Kong University, promoter of the mangrove survey in Hong Kong.

\section{Material examined}

Holotype

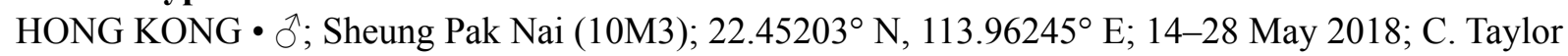
and Cheung Shun Chi leg.; RBINS. 


\section{Paratypes}

HONG KONG • 1 ``; To Kwa Peng (29M3); $22.42907^{\circ}$ N, $114.33326^{\circ}$ E, 8-25 May 2018; C. Taylor and Cheung Shun Chi leg.; RBINS • 2 우; To Kwa Peng (29M4); $22.42804^{\circ} \mathrm{N}, 114.33467^{\circ}$ E; 25 May-10 Jun. 2018; C. Taylor and Cheung Shun Chi leg.; HKU • 1 क; Yim Tin Tsai (45AM2); $22.37513^{\circ} \mathrm{N}$, 114.30168 E, 16 May-1 Jun. 2018; C. Taylor and Cheung Shun Chi leg.; HKU • 1 ㅇ; Tai O (17CM1); $22.25790^{\circ} \mathrm{N}, 113.86360^{\circ}$ E; 20 Oct. -2 Nov. 2017; C. Taylor and U. Chang leg.; RBINS • 1 q; Tsim

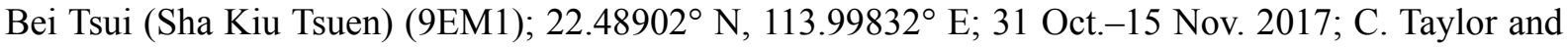
U. Chang leg.; muddy back mangrove; RBINS • 1 क ; Sam A Chung (5BM1); $22.50829^{\circ} \mathrm{N}, 114.27248^{\circ} \mathrm{E}$; 11-27 Dec. 2017; C. Taylor and U. Chang leg.; sandy back mangrove; RBINS.

\section{Barcodes}

>doli_HKC0000281_Kareen-Nabilah_INTRN223_HongKong_31Dec9999_20180820 female Tai O (the other side) $17 \mathrm{CM} 1$

GAATAAATGTTGGTAAAGTACTGGATCTCCTCCTCCAGCTGGGTCAAAGAATGATGTATT TAGATTACGATCAGTTAATAATATTGTAATAGCTCCAGCTAAAACAGGTAATGATAATAAT AAAAGAATAGCTGTAATAACTACAGATCATACAAATAATGGTATTCGATCAAGAGTAATTC CTGTTGATCGTATATTAATTACAGTAGTAATAAAATTTACTGCCCCTAAAATAGATGAAATAC CTGCCAAGTGAAGAGAGAAAATAGCCAAGTCAACAGAAGCACCTCCATGGGCAATTCCAG CTGATAAT

>doli_HKC0000914_Nabilah_INTRN225_HongKong_31Dec9999_20180820 female Tsim Bei Tsui (Sha Kiu Tsuen) 9EM 1

GAATAAATGTTGGTAAAGTACTGGATCTCCTCCTCCAGCTGGGTCAAAGAATGATGTATT TAGATTACGATCAGTTAATAATATTGTAATCGCTCCAGCTAAAACAGGTAATGATAATAAT AAAAGAATAGCTGTAATAACTACAGATCATACAAATAATGGTATTCGATCAAGAGTAATTC CTGTTGATCGTATATTAATTACAGTAGTAATAAAATTTACTGCCCCTAAAATAGATGAAATAC CTGCCAAGTGAAGAGAGAAAATAGCCAAGTCAACAGAAGCACCTCCATGGGCAATTCCAG CTGATAAT

>doli_HKC0000251_Kareen-Nabilah_INTRN223_HongKong_31Dec9999_20180820 female Sam A Chung 5BM1

GAATAAATGTTGGTAAAGTACTGGATCTCCTCCTCCAGCTGGGTCAAAGAATGATGTATT TAGATTACGATCAGTTAATAATATTGTAATAGCTCCAGCTAAAACAGGTAATGATAATAA TAAAAGAATAGCTGTAATAACTACAGATCATACAAATAATGGTATTCGATCAAGAGTAAT TCCTGTTGATCGTATATTAATTACAGTAGTAATAAAATTTACTGCCCCTAAAATAGATGAAAT ACCTGCCAAGTGAAGAGAGAAAATAGCCAAGTCAACAGAAGCACCTCCATGGGCAATTCC AGCTGATAAT

\section{Description}

\section{Male}

MEASUREMENTS. Body: 4.32-4.48 mm long; wing: 3.52-3.84 mm long.

HEAD. Upper ten postocular bristles short, uniseriate, black; lower postoculars long, white, multiseriate, forming a favoris. Antenna black. Pedicel with a crown of apical bristles, dorsal bristle longer than pedicel. Postpedicel elongate triangular, 1.6-1.7 $\times$ as long as wide. Arista 1.6-2 $\times$ as long as postpedicel. Palpus black, with black bristles.

THORAX. Shining metallic green. 4 pairs of irregularly set acrostichals, shorter than the five long dc.

WING. Brownish tinged, veins yellowish brown. Squama white, with a fan of long white cilia. 
LEGS. Yellow with a pattern. Fore coxa exteriorly black on basal half, yellow on apical half. Mid and hind coxae black. Fore femur yellow. Fore and mid tarsomeres 4-5 brown. Apical quarter of hind femur black. Base of hind tibia narrowly black, apical third black. All hind tarsomeres black.

FORE LEG. Fore coxa on basal half covered with long pale hairs and bristles; near base only white bristles, from apical half onward mixed with black bristles. Femur with a ventral row of fine white bristles, half as long as width of femur; four black preapical posterodorsal bristles, as long as depth of femur; a row of posterior black bristles over entire length, as long as width of femur. Tibia with three dorsal bristles, basalmost half as long as second and third bristle; no apical crown of bristles.

MID LEG. Coxa without exterior bristles but anteriorly densely set with black bristles, mixed with a few fine pale bristles; tip with a number of adhered bristles forming a thorn (spur). Femur without ventrals; two fine anterior preapicals; two longer posterior preapicals. Tibia with three anterodorsal and three posterodorsal bristles; an apical crown of strong bristles.

HIND LEG. Coxa with a few pale anterior hairs and two stronger black exterior bristles just above tip (a long upper and a short lower bristle). Femur with a strong anterior preapical and a shorter posterior preapical; a short row of anteroventral preapicals; no ventrals. Tibia with three anterodorsals and three posterodorsal bristles, a crown of strong apicals.

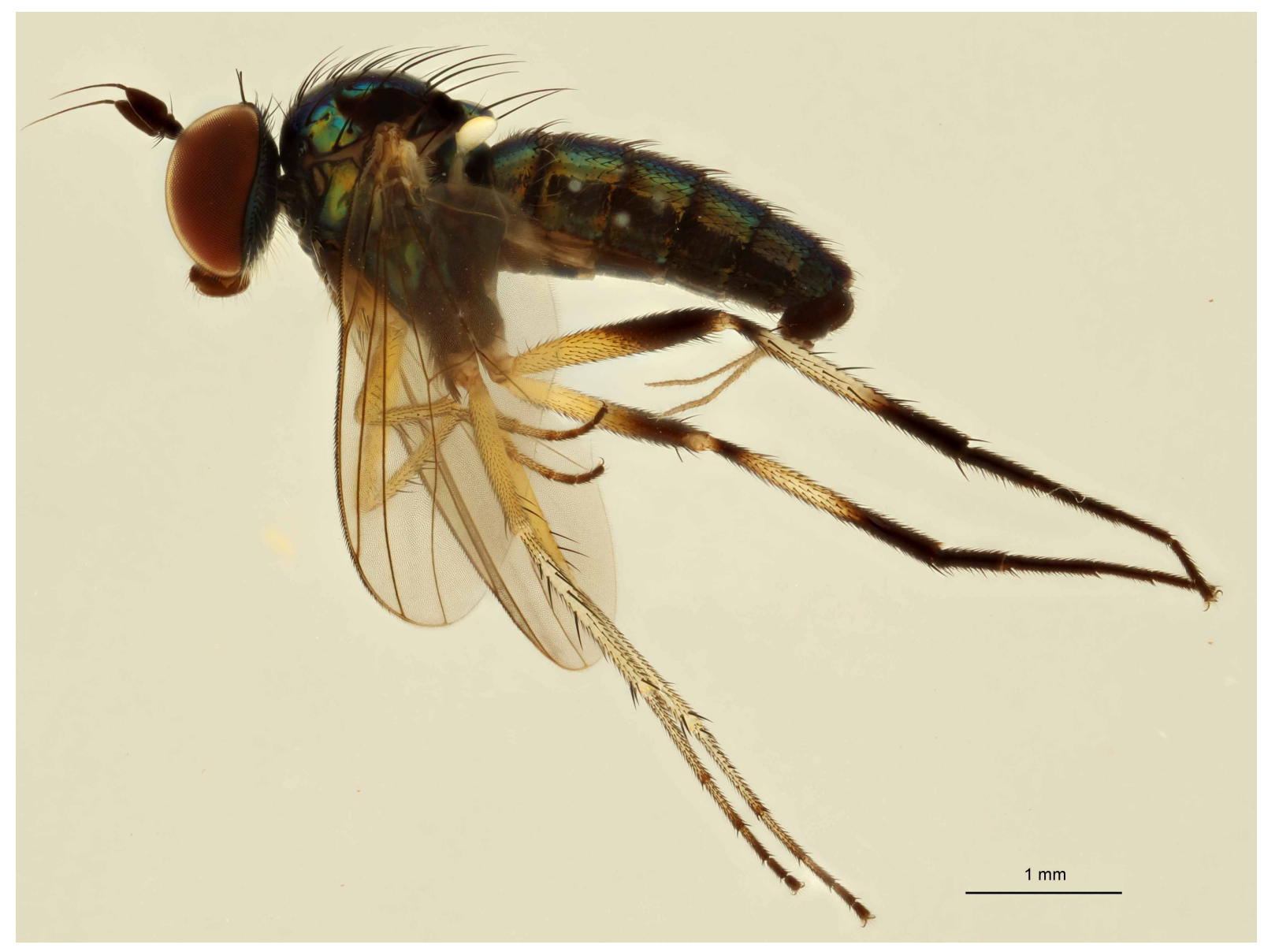

Fig. 5. Rhaphium canniccii sp. nov., holotype, $\partial^{\lambda}$, habitus (RBINS). Scale bar: $1 \mathrm{~mm}$. (Photo credit Ms Camille Locatelli) 
ABDOMEN. Shining metallic green. First tergite set with long pale hairs at sides and some black marginals. Tergites 2 and 3 dorsally with short black bristles and long pale bristles at sides.

Male terminalia (Fig. 6). Cercus very long, nearly twice as long as genital capsule (Fig. 6C), wide on basal third. Tip of hypandrium pointing up ventrally and with a clockwise twist. Surstyli rounded in lateral view (Fig. 6D).

\section{Female}

Measurements. Body: 4.5-4.6 mm long; wing: $3.8 \mathrm{~mm}$ long.

HEAD. Antenna: scape: $0.09 \mathrm{~mm}$; pedicel: $0.065 \mathrm{~mm}$; postpedicel: $0.13 \mathrm{~mm}$; arista: $0.52 \mathrm{~mm}$. Postpedicel triangular, $1.5 \times$ as long as wide. Arista $4 \times$ as long as postpedicel.

FORE COXA. Entirely yellow, anteriorly set with long white bristles, only the apical bristles black. Mid coxa anteriorly with long, fine white bristles mixed with a few black bristles; apex with a few black

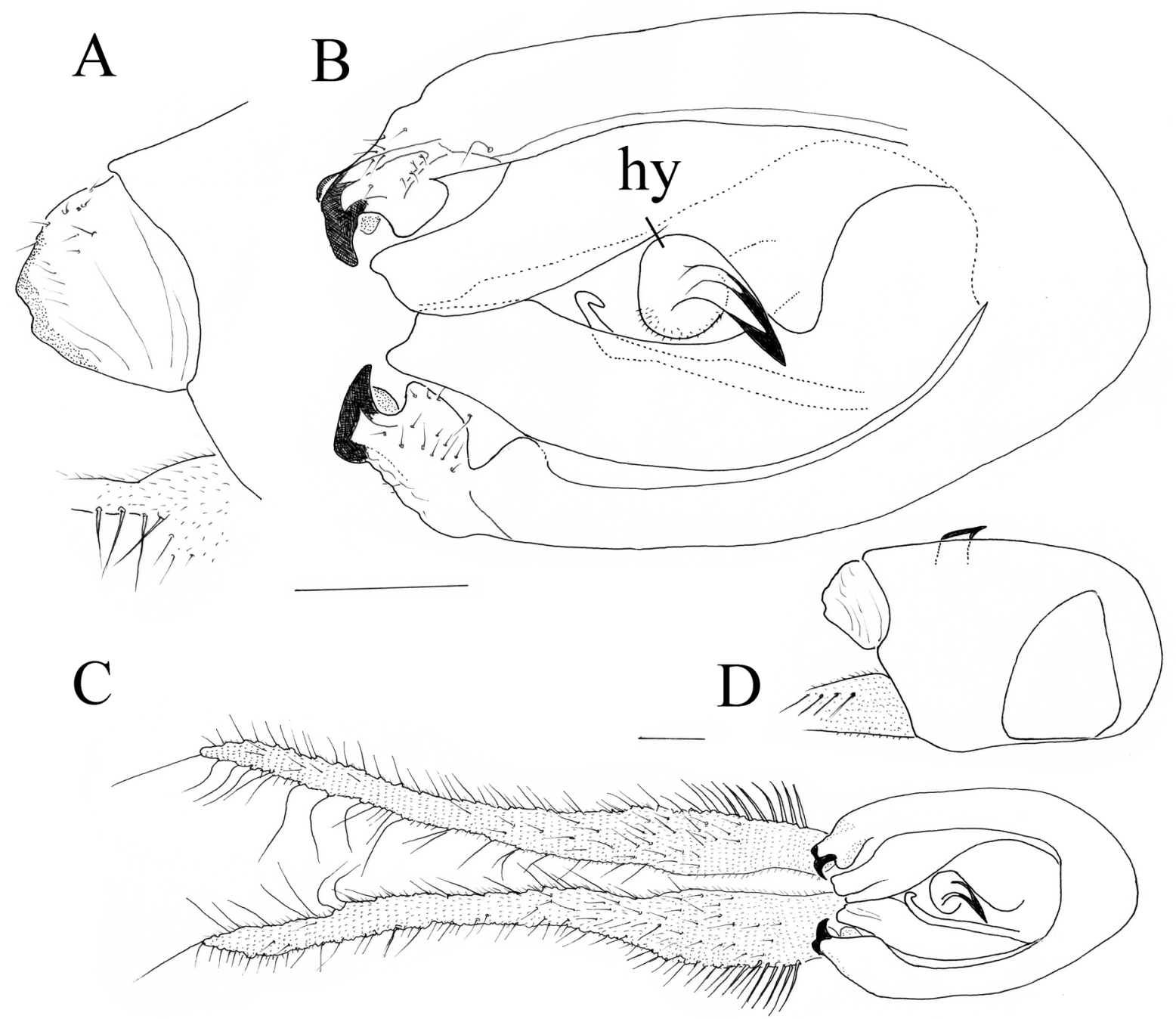

Fig. 6. Rhaphium canniccii sp. nov., holotype, $\widehat{\partial}$, terminalia (RBINS). A. Surstylus, lateral view. B. Epandrium, ventral view. C. Epandrium with cerci ventral view. D. Epandrium, lateral view. Abbreviation: hy $=$ hypandrium. Scale bars: $0.1 \mathrm{~mm}$. 
bristles, not forming a spur as in male. Sides of tergites 1, 2 and 3 also with white bristles, but shorter than in male. Wing darker brownish tinged than in male.

\section{Remarks}

There is a sexual dimorphism in this species in the colour of the fore coxa, which is almost entirely black on the basal half in the male but entirely yellow in the female. This is also the case in the female of Rhaphium mediocre (Becker, 1922) and R. eburnea (Parent, 1926), to which R. canniccii sp. nov. is closely related.

Rhaphium eburnea has been considered to be a junior synonym of $R$. mediocre (Negrobov 1979; Yang et al. 2011). However, examination of the type material of the two species supports their recognition as distinct. Becker (1922) described the postpedicel in $R$. mediocre as twice as long as wide and the arista as equally long. A photo of the lectotype male shows that the arista is at most $1.2 \times$ as long as the postpedicel (Fig. 7). Parent (1926) described the postpedicel in R. eburnea as being twice as long as wide, and the arista as about $1.5 \times$ as long as the postpedicel. However, in the lectotype male the arista is $3 \times$ as long as the postpedicel (Fig. 8). In R. canniccii sp. nov., the postpedicel is shorter than in both other species, $1.6-1.7 \times$ as long as wide, with the arista $1.6-2 \times$ as long as the postpedicel. In the redescription of $R$. mediocre given by Yang et al. (2011: fig. 806) the arista is described as $2 \times$ as long as the postpedicel. This was based on new material collected in Shanghai and not on the type material of either of the two species. Hence, it is not unlikely that another, yet undescribed species is involved.

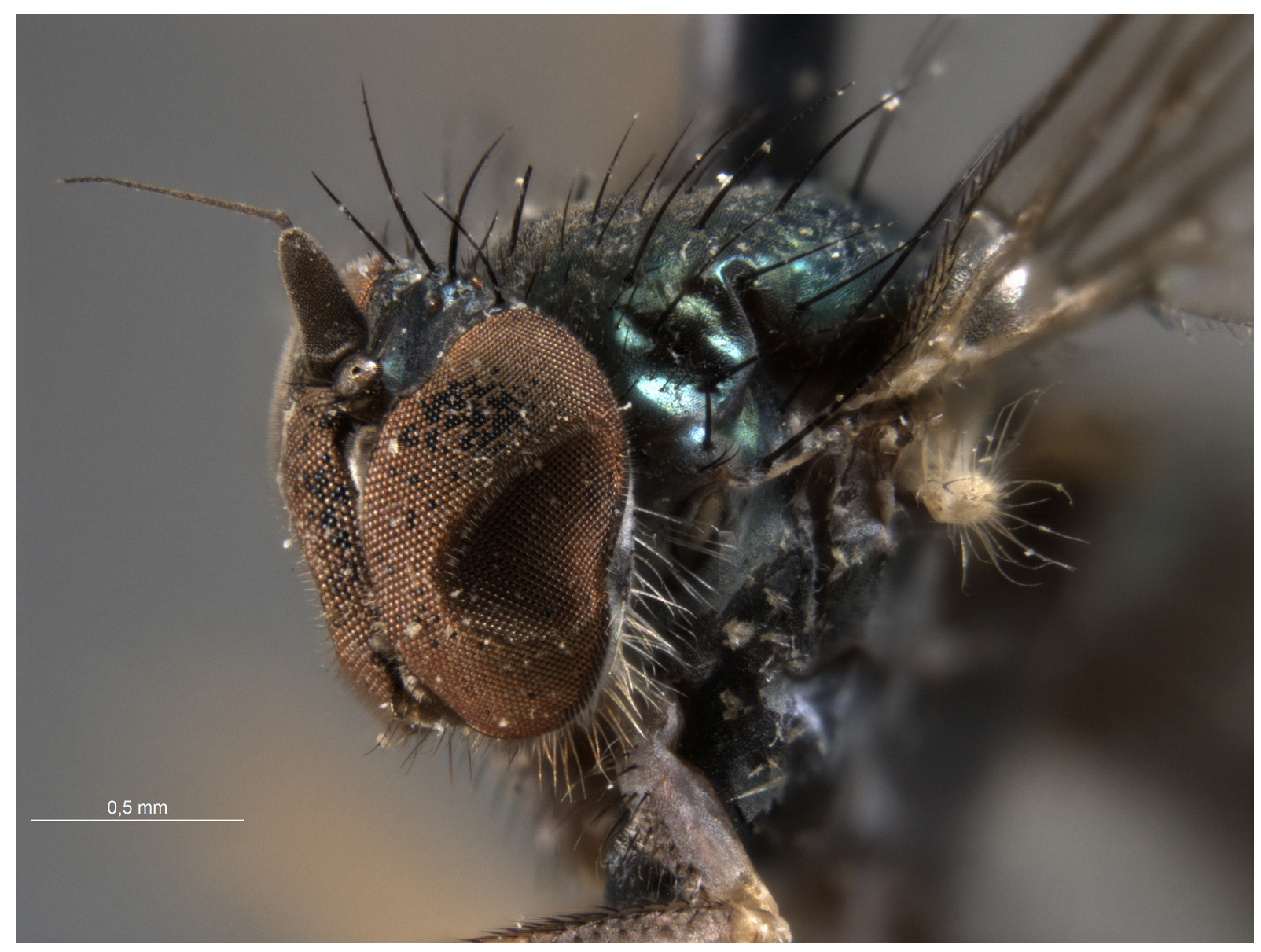

Fig. 7. Rhaphium mediocre (Becker, 1922), lectotype, đ, head in lateral view (coll. mfn-berlin). (Photo credit Mr Bernhard Schurian and Sven Marotske) 
Negrobov (1979: fig. 1817) illustrated the male terminalia of $R$. mediocre based on the lectotype and that figure was copied in Yang et al. (2011: fig. 806c). The tip of the hypandrium turns counter-clockwise in $R$. mediocre but clockwise in $R$. canniccii sp. nov. (Fig. 6). In $R$. mediocre, the fore coxa is covered with black bristles (Fig. 9) and the basal segment of the arista is shorter than in $R$. canniccii sp. nov. (Fig. 7 and Fig. 5, respectively).

As yet, only a small number of species groups have been recognised within Rhaphium and that on the basis of selected unusual characters, with the majority of species as yet unplaced in species groups (Tang et al. 2016). An extensive revision of relationships within this large and complex genus is beyond

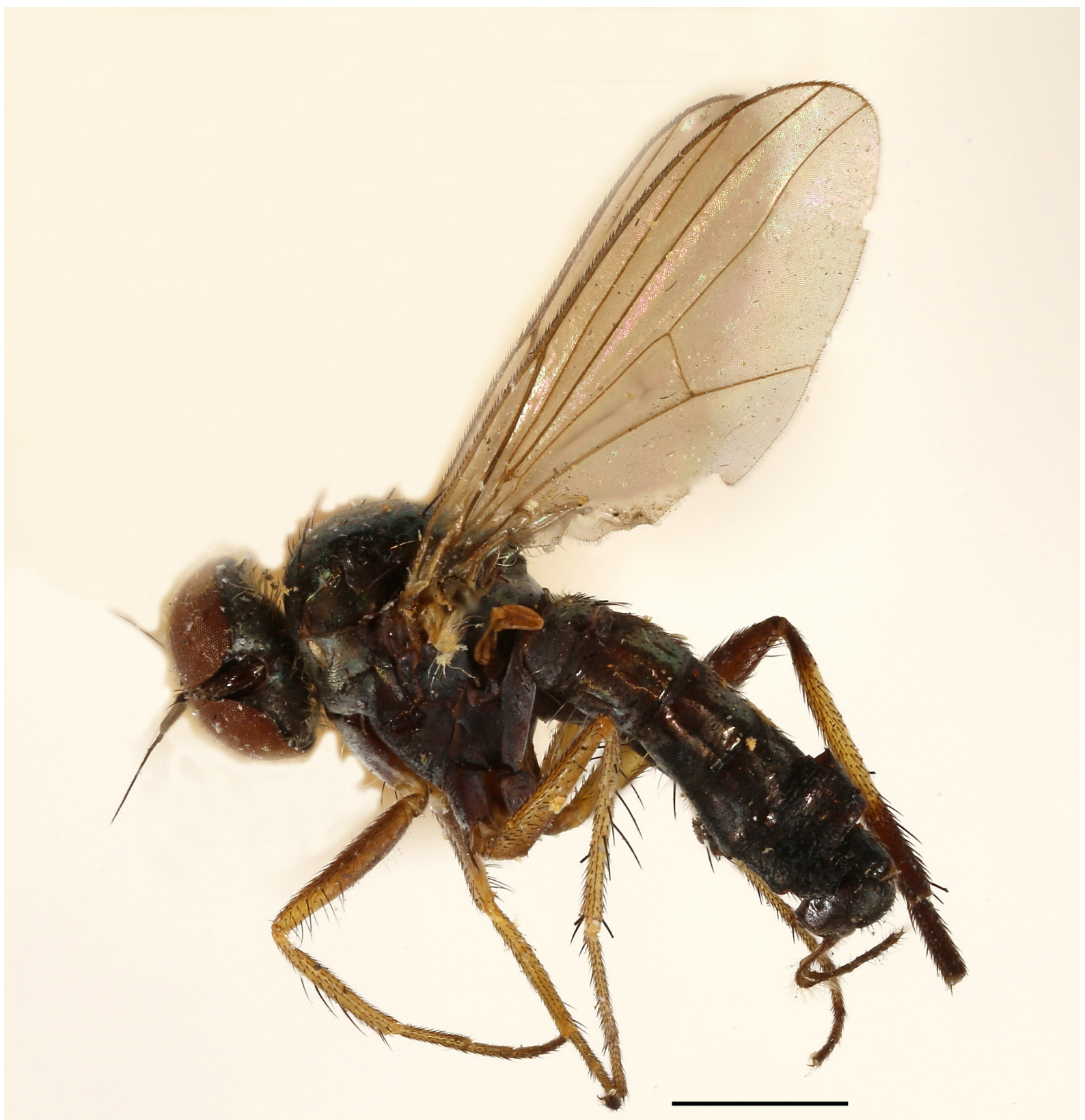

Fig. 8. Rhaphium eburnea (Parent, 1926), lectotype, $\widehat{\partial}$, habitus (MNHN). (Photo credit Mr Emmanuel Delfosse, MNHN) 
the scope of the present paper. Nevertheless, a group of species related to Rhaphium micans (Meigen, 1824) may be recognised as having a postpedicel (first flagellomere) at most $2.5 \times$ as long as wide with a longer arista (1.2 to $3 \times$ as long as the postpedicel), $5 \mathrm{dc}$, long flattened cerci (nearly twice as long as epandrium), short surstyli that are rounded in lateral view and a twisted erect hypandrium. Members of this group include $R$. bisectum Tang et al., 2016, R.cannicii sp. nov., $R$. dispar Coquillet, 1898, $R$. eburnea, $R$. gansuanum Yang, 1998, $R$. lumbricus Wei, 2006, $R$. mediocre, $R$. micans, $R$. tianshuiense Qilomoge et al., 2019 and $R$. wuduanum Wang et al., 2005.

\section{Rhaphium eburnea (Parent, 1926)}

Fig. 8

Porphyrops eburnea Parent, 1926: 139 (type locality: Zi-Ka-Wei, Shanghai, China).

\section{Diagnosis}

Larger species $(5 \mathrm{~mm})$. Male: legs yellow except for all coxae black, fore femur dorsally black, tip of hind femur, base and tip of hind tibia and apical 2 tarsomeres of fore and mid leg and all hind tarsomeres black. Postpedicel elongate triangular, twice as long as wide, arista $3 \times$ as long as postpedicel. Fore coxa with long bristles, near base with white bristles, on apical half white bristles mixed with black bristles. Tip of mid coxa with a number of adhering bristles forming a thorn.

\section{Type material}

\section{Syntypes}

CHINA - Shanghai • 1 ภ, 2 + $\odot$; Zi-Ka-Wei; 17 May 2017; MNHN • 1 + ; Kao Gkiao; 23 Oct. 2017; MNHN [as communicated by Mr Emmanuel Delfosse, Paris].

Rhaphium mediocre (Becker, 1922)

Figs 7, 9

Porphyrops mediocris Becker, 1922: 59 (type localities: Taihoku and Kankau, Taiwan).

Rhaphium mediocre - Negrobov 1979: 511, figs 1816-1818 (fig. 1816: lectotype male terminalia, lateral view; fig. 1817: epandrium, ventral view; fig. 1818: cercus, dorsal view). — Yang et al. 2011: 1277, fig. 806. — Tang et al. 2016 (key).

\section{Diagnosis}

Medium-sized species (3.2 mm). Male: legs yellow except fore coxa black, fore femur dark brown, tip of hind femur, base and tip of hind tibia and all hind tarsomeres black. Postpedicel elongate triangular, twice as long as wide, arista $1.2 \times$ as long as postpedicel. Postocular bristles black, mixed with some white bristles. Fore coxa with long black bristles only. Tip of mid coxa with a number of adhered bristles forming a thorn. Hind coxa with a long and a short black exterior bristle near tip.

\section{Type material}

\section{Lectotype}

TAIWAN • ô; Taipei; H. Sauter leg.; 1912; see Fig. 9 inset for the labels; Museum für Naturkunde, Berlin; MfN.

\section{Remarks}

The type locality of the lectotype is Taihoku in Taiwan, an alternative name for modern Taipei. Becker (1922) mentions one male and three females from Taihoku and Kankau, April 1912 (leg. Sauter) in the 
Hungarian National Museum. It is likely that these have been destroyed. Furthermore, he mentions two males and two females from Taihoku, November 1912 (leg. Sauter), which are now held by the Museum für Naturkunde in Berlin. A lectotype male was designated by Negrobov (1979) and the male terminalia were drawn and published.

More differences are provided under the comments on $R$. canniccii sp. nov.

\section{Key to the Chinese Rhaphium micans group, modified after Qilemoge et al. (2019)}

Species with postpedicel at most $2.5 \times$ as long as wide; fore tarsus simple; fore femur without strong ventral bristles or long hairs, at most half as long as width of femur. Note that $R$. lumbricus also belonging to the micans-group has the fore tarsomere 1 dorsally depressed, but is strongly raised ventrally (Qilemoge et al., loc. cit.).

21. Fore tarsomere 1 with row of strong ventral bristles on basal half, tarsomere 2 inflated apically (Yang et al. 2011: fig. 807c)

- Fore tarsomere 1 without distinct ventral bristles, tarsomere 2 simple 23

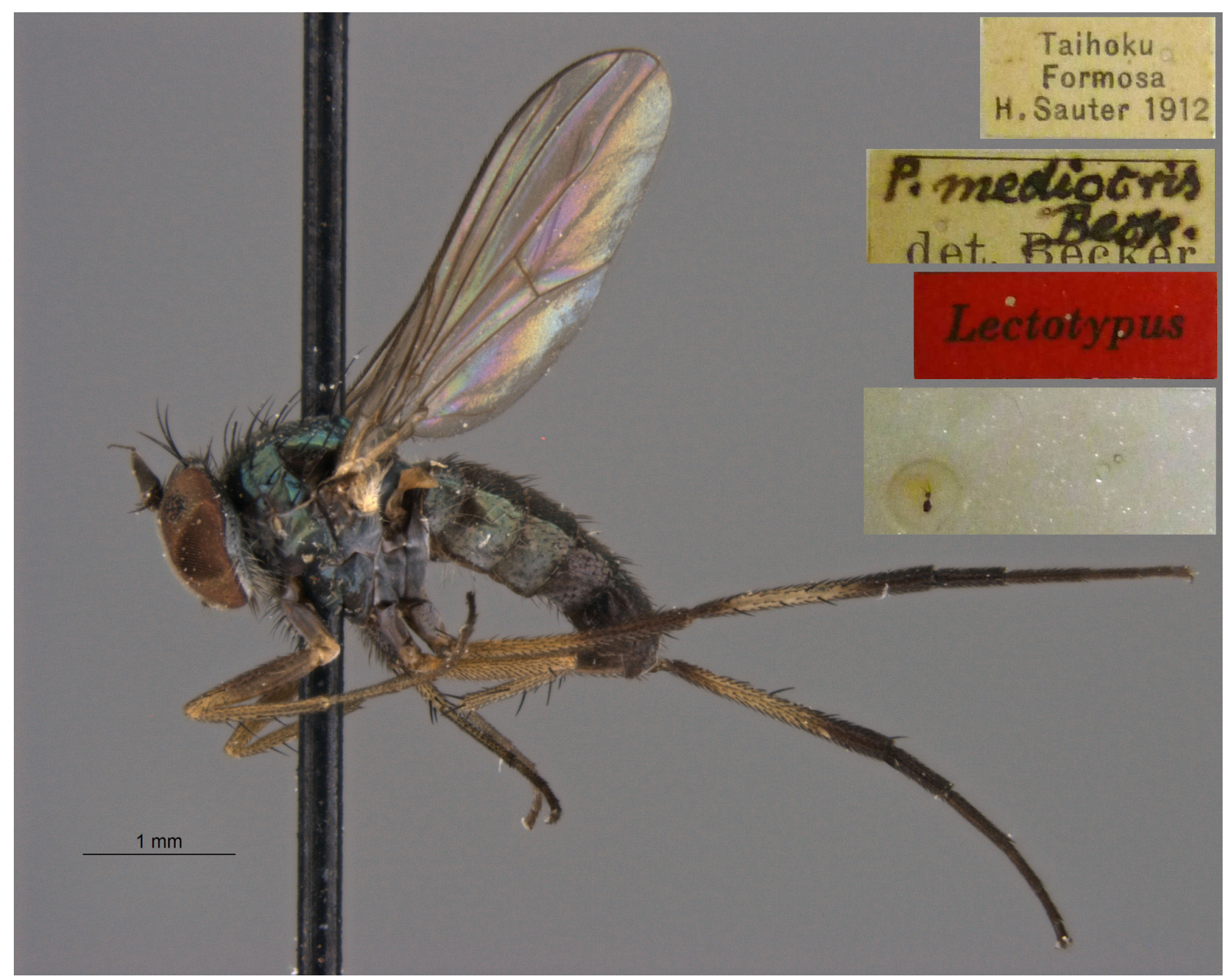

Fig. 9. Rhaphium mediocre (Becker, 1922), lectotype, $\widehat{\jmath}$, habitus, with labels and preparation of male terminalia on plastic sheet (MfN). (Photo credit Mr Bernhard Schurian and Sven Marotske) 
22. Fore and mid femora yellow apically, fore and mid tibia yellow; fore coxa with black bristles and hairs

R. micans (Meigen, 1824)

- Fore femur, mid and hind tarsi dark; fore coxa with light yellow bristles and hairs

R. dispar Coquillett, 1898

23. All coxae dark, fore and mid femora yellow apically

- Basal half of fore coxa and apical $1 / 3$ of hind femur dark 25

24. Hind tibia with 3 ventral bristles; mid tarsomere $11.1 \times$ as long as hind tarsomere 1

R. wuduanum Wang, Yang \& Masunaga, 2005

- Hind tibia without distinct ventral bristles; mid tarsomere $11.4 \times$ as long as hind tarsomere 1

R. gansuanum Yang, 1998

25. Mid coxa with 1 strong outer bristle and bunch of ventral bristles; mid tibia with 1 anteroventral ...

- Mid coxa only with only 1 strong outer bristle at middle, without bunch of ventral bristles; mid tibia without ventral bristles

R. bisectum Tang, Wang \& Yang, 2016

26. Squama with yellow hairs; cercus not bifoliate; surstylus short and thick (Fig. 6)

- Squama with black hairs; cercus bifoliate; surstylus basally thick, apically sharp, with one protuberance

R. tianshuiense Qilemoge, Wang \& Yang, 2019

27. Postpedicel less than twice as long as wide (between 1.6-1.7 $\times$ ), arista at most $2 \times$ as long as postpedicel; fore femur entirely yellow (Fig. 5)

R. canniccii sp. nov.

- Not with this combination of characters. Postpedicel $2 \times$ as long as wide. Fore femur brownish above dorsally

28. Postpedicel twice as long as wide, arista at most $1.2 \times$ as long as postpedicel (Fig. 7)

R. mediocre (Becker, 1922)

- Postpedicel twice as long as wide, arista $3 \times$ as long as postpedicel (Fig. 8)

R. eburnea (Parent, 1926)

\section{Discussion}

To our knowledge, the species presented here represent the first species of the genus Rhaphium adapted to live within mangrove ecosystems. The specimens collected were abundant and widespread across the mangroves sampled, with over 160 specimens collected at six sites for $R$. hongkongense sp. nov., while over 400 specimens were collected at nine sites for $R$. spinulatum sp. nov. The third species, Rhaphium canniccii sp. nov., was far less common with eight specimens, but collected at six different mangrove sites. As the Malaise traps were set well within the mangroves, it seems unlikely that these specimens were accidental collections from nearby terrestrial habitats. It was also remarkable that the specimens were collected towards the end of the year (late October to early January) in a cooler and drier climate period; air temperatures measured during this period averaged $19.9^{\circ} \mathrm{C}$, with the range being 9.8 to $28.4^{\circ} \mathrm{C}$ (Hong Kong Observatory 2017) which points to a tight Palaearctic relationship.

\section{Acknowledgements}

The Hong Kong Mangroves project is supported by the Environment and Conservation Fund (ECF Project 69/2016). We thank Ms Ukyoung Chang for her help in taking and sorting the samples, and Dr Stefano Cannicci for his lead in the mangrove project. 
Further, we heartily thank Prof Rudolf Meier of the National University of Singapore (NUS), as well as Mrs Jayanthi Puniamoorthy (NUS) and her team, who did the NGS-barcodes of the specimens. Thanks are also due to Ms Camille Locatelli (Royal Belgian Institute of Natural Sciences, Brussels) for taking the stacked photographs of the new species, as well as to Mr Emmanuel Delfosse and Dr Christophe Daugeron (Muséum national d'Histoire naturelle, Paris) and to Mr Bernhard Schurian and Mr Sven Marotze (Museum für Naturkunde, Berlin) for photographing the other species.

\section{References}

Becker T. 1922. Dipterologische Studien. Dolichopodidae der indo-australischen Region. Capita Zoologica 1 (4): 1-247.

Brecko J., Mathys A., Dekoninck W., Leponce M., VandenSpiegel D. \& Semal P. 2014. Focus stacking: comparing commercial top-end set-ups with a semi-automatic low budget approach. A possible solution for mass digitization of type specimens. Zookeys 464: 1-23. https://doi.org/10.3897/zookeys.464.8615

Grootaert P. 2006. The genus Teuchophorus (Diptera, Dolichopodidae) in Singapore. Raffles Bulletin of Zoology 54: 59-82.

Grootaert P. 2009. Oriental Diptera, a challenge in diversity and taxonomy. In: Papp T., Bickel D. \& Meier R. (eds) Diptera Diversity: Status, Challenges and Tools: 197-226. Koninklijke Brill N.V., Leiden.

Grootaert P. \& Puniamoorthy J. 2014. Revision of Ngirhaphium (Insecta: Diptera: Dolichopodidae), with the description of two new species from Singapore's mangroves. Raffles Bulletin of Zoology 62: 146-160.

Hong Kong Observatory. 2017. Daily Extract for 2017.

Available from https://www.hko.gov.hk/cis/dailyExtract_e.htm?y=2017\&m=11 [accessed 6 Nov. 2018].

Meier R., Wong W., Srivathsan A. \& Foo M. 2016. \$1 DNA barcodes for reconstructing complex phenomes and finding rare species in specimen-rich samples. Cladistics 32: 100-110. https://doi.org/10.1111/cla.12115

Naglis S. 2009. Some taxonomical changes in the genus Rhaphium (Diptera, Dolichopodidae), with a key to the Rhaphium albifrons species group. Mitteilungen der Schweizerischen Entomologischen Gesellschaft 82: 201-203.

Naglis S. \& Grootaert P. 2011. A remarkable new species of Rhaphium Meigen (Diptera, Dolichopodidae) from Sri Lanka. Zootaxa 2991: 44-48.

Negrobov O.P. 1979. Dolichopodidae. In: Lindner E. (ed.) Die Fliegen der Palaearktischen Region. Lieferung 322: 475-530, pls 189-207. E. Schweizerbart'sche Verlagsbuchhandlung, Stuttgart.

Negrobov O.P. \& Grichanov I.Y. 2010. The Rhaphium crassipes species group in the Palearctic Region with the description of a new species from Uzbekistan (Diptera: Dolichopodidae). Caucasian Entomological Bulletin 6 (1): 117-122.

Parent O. 1926. Dolichopodidés nouveaux de l'extrême orient paléarctique. In: Encyclopédie entomologique. Serie B. II. Diptera. Vol. 3: 111-149. Paris.

Qilemoge, Wang M. \& Yang D. 2019. Three new species of Rhaphium from China, with an updated key to Chinese Rhaphium (Diptera, Dolichopodidae, Rhaphiinae). ZooKeys 840: 87-99. https://doi.org/10.3897/zookeys.840.31602

Ramos K. \& Grootaert P. 2018. Description of a new mangrove Hercostomus (Diptera: Dolichopodidae: Dolichopodinae) from Bohol, Philippines. Tropical Natural History 18 (1): 24-31. 
Tam N.F.Y. \& Wong Y.S. 2002. Conservation and sustainable exploitation of mangroves in Hong Kong. Trees 16: 224-229.

Tang C., Wang N. \& Yang D. 2016. Rhaphium (Diptera: Dolichopodidae: Rhaphiinae) from China with six new species. Zootaxa 4162 (3): 581-593. https://doi.org/10.11646/zootaxa.4162.3.11

Yang D., Zhang L., Wang M. \& Zhu Y. 2011. Diptera Dolichopodidae, Rhaphiinae Bigot, 1852. Fauna Sinica Insecta. Vol. 53: 1241-1273. Science Press, Beijing.

Yang D., Zhu Y.J., Wang M. \& Zhang L. 2006. World Catalog of Dolichopodidae (Insecta: Diptera). China Agricultural University Press, Beijing.

Zhang L., Yang D. \& Grootaert P. 2007. Paraclius (Diptera: Dolichopodidae: Dolichopodinae) of Singapore, with new species from mangroves. Raffles Bulletin of Zoology 55: 49-62.

Zhang L., Yang D. \& Grootaert P. 2008. Mangrove Hercostomus sensu lato (Diptera: Dolichopodidae) of Singapore. Raffles Bulletin of Zoology 56: 17-28.

Manuscript received: 15 May 2019

Manuscript accepted: 13 June 2019

Published on: 30 July 2019

Topic editor: Gavin Broad

Desk editor: Kristiaan Hoedemakers

Printed versions of all papers are also deposited in the libraries of the institutes that are members of the EJT consortium: Muséum national d'Histoire naturelle, Paris, France; Meise Botanic Garden, Belgium; Royal Museum for Central Africa, Tervuren, Belgium; Royal Belgian Institute of Natural Sciences, Brussels, Belgium; Natural History Museum of Denmark, Copenhagen, Denmark; Naturalis Biodiversity Center, Leiden, the Netherlands; Museo Nacional de Ciencias Naturales-CSIC, Madrid, Spain; Real Jardín Botánico de Madrid CSIC, Spain; Zoological Research Museum Alexander Koenig, Bonn, Germany; National Museum, Prague, Czech Republic. 